\title{
ASSESSMENT AND MANAGEMENT OF ARTICULATION AND PHONOLOGICAL DISORDERS IN SCHOOL CHILDREN IN GHANA
}

\author{
A. Osei-Bagyina \\ Department of Eye, Ear, Nose and Throat, \\ School of Medical Sciences, \\ Kwame Nkrumah University of Science and Technology, \\ Kumasi, Ghana
}

\begin{abstract}
Thirty regular school children with functional articulation and phonological disorders, aged 7; 0 to 17; 11, were involved in the study. They were screened for speech defects from selected schools in the Kumasi metropolis. Effects of maturation were controlled for by the inclusion of only children of seven years and above who had reached their limit for spontaneous acquisition of phonemes by adult standards. The study investigated the children's age versus their school grades, their class performance, the emergence of their speech and language milestones, differences in their speech mechanisms, the intelligibility of their speech and the treatment outcome. The result indicated a sex ratio of 1:6.5 females to males. Only 10\% of the children were in their normal school grade level while $90 \%$ were in various grade levels below the normal. Fifty percent were rated as below average, 46.7\% as average and 3.3\% as below average. Considering the time for speech and language acquisition, $63.3 \%$ were considered normal while the rest were considered delayed. While $50 \%$ had "normal" tongue, 16.7\% had ankyloglossia, 30\% had limited tongue movement and $3.3 \%$ had macroglossia. However these tongue differences were considered insignificant due to the adequacy of the tongue structure in its performance. Twenty percent sounded hypernasal but correction of their misarticulations solved their problems. Baseline intelligibility rates were: moderate-30\%; moderate-severe $30 \%$, and severe-40\%. Therapy gains were $90-100 \%$ for $73.3 \%$ of the children; $70-80 \%$ for $20 \%$ of them and $50-60 \%$ for $6.7 \%$ of the rest. By these gains, the children had improved skills for effective communication, a great sense of pride and confidence and a fully active social life.
\end{abstract}

Keywords: Articulation disorders, phonological disorders, phonemes, intelligibility.

\section{INTRODUCTION}

Articulation is, simply, the process of producing and using phonemes or speech sounds of one's linguistic community. If one's articulatory or phonological productions are consistently at variance with cultural or age norms, they are said to constitute a disorder. The age of the producer and the normative data relative to the age at which 
specific phonemes are acquired are determinants for the presence or absence of a disorder. It is generally agreed that by the second grade or seven years of age most children have acquired normal articulation as judged by adult standards (Weiss et al., 1980; Boone and Plante, 1993).

Articulation errors consist of omission (deletion of sounds), substitution (using one sound for another), distortion (changing sounds slightly by addition of noise or a change in voicing) and infrequently, addition (adding extra sound to those provided) (Boone and Plante, 1993; Wikipedia, 2007). In terms of listener perception and understanding, sound omission or deletion is the most pronounced type of error commonly related with the speech of younger children. Sound substitution is very common in the speech of school aged children and does not affect intelligibility as much as the former. Sound distortion involves the use of close approximation of the target phoneme and is related to the speech of older children and adults (Bernthal and Bankson, 1989; Weiss et al., 1980).

Articulation and phonological disorders may be attributed to various causes; for example, hearing loss, oral-motor problems such as apraxia (a problem with coordination of speech muscles) or dysarthria (abnormal facial tone, often due to neurological problems such as cerebral palsy), and structural abnormalities such as cleft palate, tongue thrust and orthodontic problems. A large number of articulation disorders have no recognizable organic, neurogenic, or physical correlate. Children with articulation disorders of unknown cause (functional disorders) constitute $99 \%$ of the caseloads of speech-language therapists working in the schools (NIH, 1994).

Disorders of articulation are the most prevalent communication disorder in childhood. According to estimates, they represent in excess of $75 \%$ of all speech disorders in children (NIH, 1994). When compared with other communicative disorders, they may appear to be the only difficulties that can occur in isolation (Bruce and
Sahlen, 1996). They are commonly referred to as the most treatable of communicative disorders but they may also be the most commonly underestimated disorders as regards ease of remediation (Weiss et al., 1980). According to Emerich and Hatten (1979), many of their most difficult cases had been children and adults with misarticulation. It is important to note that children with functional articulation disorders may have consequences throughout their life span (NIH, 1994).

The purpose of this study was to investigate the subjects' age versus their school grades, their class performance, the emergence of their early speech and language milestones, differences in their speech mechanisms, the intelligibility of their speech and finally, the therapy outcome.

\section{MATERIALS AND METHODS}

A hearing and screening exercise was conducted for selected Primary, Junior and Senior High Schools in the Kumasi Metropolis and its environs. The schools were selected by simple random sampling (Amedofu et al., 2003). The screening was done by informal interview of the children who were asked to say their own names, names of the days, the months and pictured objects, and also, to count and answer open-ended questions. In all it took about 5 minutes to elicit from each child speech sample which the speech and language therapist (SLT) quickly used to evaluate the various parameters of speech (Oyer, 1994; Wikipedia, 2007). A pass meant there was no speech fault detected but a fail meant a speech problem had been detected. Failures of the screening test and their parents were invited to the Hearing and Speech Assessment Centre at the Ear, Nose and Throat (ENT) Unit of Komfo Anokye Teaching Hospital (KATH), Kumasi for individual diagnostic evaluation.

Each child was referred for a hearing test (Amedofu et al., 2003). Children who passed the test had their case history taken. A visual examination of the oral cavity and throat was done to determine whether the physical structures appeared capable of speech production. The tests of

20 Journal of Science and Technology, Vol. 28, No. 2, August, 2008 
articulation of speech sounds, spontaneous speech, fluency and voice were selectively done, depending on their need, for each child. The results were reviewed and the SLT used the information gathered to determine whether or not there was a need for speech therapy. The 30 subjects for this study were those who were seven years and above and passed the hearing and other tests but failed in the articulation test. Their oral mechanism, neuromotor, behaviour and intellectual conditions were all considered normal, or within normal range. The seven year age limit was used as a limit for spontaneous acquisition of phonemes to control maturation effects. Their school records were collected as material for the study. Intervention lasted 10 weeks; each child had two forty-five minutes contact periods a week. In all, each child received 15 hours training after which the results were put together for study.

\section{RESULTS AND DISCUSSION}

The sex ratio of 1:6.5 females to males (Table 1) in this study of 30 subjects offers support to the fact that, in Ghana as elsewhere, females frequently demonstrate better articulation skills than males, and that males are more frequently identified as having articulation problems than females (Osei-Bagyina, 2000a).

Normal children of seven and eight years are in the first and second grades (G) respectively (Table 1) but out of their 12 counterparts constituting $40 \%$ in this study, $20 \%$ were in the Kindergarten $(\mathrm{KG})$ and the other $20 \%$ were in the lower grades (LG) i.e. $\mathrm{G}$ one to three (Table 2). Only one LG child $(3.3 \%)$ was in $\mathrm{G} 2$, i.e., within the normal level but the rest were in G.1, i.e., below the normal grade level. In the second group of nine children $(30 \%)$ aged $9-11$ years, $13.3 \%$ were in $\mathrm{KG} ; 16.7 \%$ were in LG but there was none in the upper grade (UG, the normal level). Similarly, only one out of five, 12-14 year-group was within the normal Junior High School (JHS) level, and one out of four, 15-17 year-group was within the normal Senior High School (SHS) level. All together, $10 \%$ of the subjects were within the normal class level while $90 \%$ were below that level. Due to their articulation problems, most of the

Table 1: Normal class level and age and sex distribution of subjects

\begin{tabular}{llccc}
\hline Age & Normal class Level & Males & Females & Total \\
\hline $7-8$ & LG 2-3 & $9(30 \%)$ & $3(10 \%)$ & $12(40 \%)$ \\
$9-11$ & UG 4-6 & $8(26.7 \%)$ & $1(3.3 \%)$ & $9(30 \%)$ \\
$12-14$ & JHS 1-3 & $5(16.7 \%)$ & 0 & $5(16.7 \%)$ \\
$15-17$ & SHS 1-3 & $4(13.3 \%)$ & 0 & $4(13.3 \%)$ \\
Total & - & $26(86.7 \%)$ & $4(13.3 \%)$ & $30(100 \%)$ \\
\hline
\end{tabular}

Table 2: Actual class level of subjects

\begin{tabular}{ccccccc}
\hline Age & KG & \multicolumn{1}{c}{ LG } & UG & JHS & SHS & Total \\
\hline $7-8$ & $6(20 \%)$ & $6(20 \%)$ & - & - & - & $12(40 \%)$ \\
$9-11$ & $4(13.3 \%)$ & $5(16.7 \%)$ & - & - & - & $9(30 \%)$ \\
$12-14$ & - & $2(6.7 \%)$ & $2(6.7 \%)$ & $1(3.3 \%)$ & - & $5(16.7 \%)$ \\
$15-17$ & - & - & - & $3(10 \%)$ & $1(3.3 \%)$ & $4(13.3 \%)$ \\
Total & $10(33.3 \%)$ & $13(43.4 \%)$ & $2(6.7 \%)$ & $4(13.3 \%)$ & $1(3.3 \%)$ & $30(100 \%)$ \\
\hline
\end{tabular}


children started school late while the few who started at the right time kept on repeating classes along the educational ladder.

Regarding general class performance, only one (3.3\%) SHS candidate was rated as above average; $46.7 \%$ were rated as average and $50 \%$ as below average (Table 3).Two below average students in JHS were repeating classes. One other 11 year old child in KG was rejected from the regular school and taken to a special school for the mentally handicapped where he was also rejected for being too good to attend that school. Because articulation is an early developing communication system, disorders are often the first manifestation of more pervasive problems including reception problems and reading and spelling difficulties (Blelle, 2002).

Concerning developmental delay, $36.7 \%$ of the subjects showed delay in language development (Table 4). Children up to five years of age with untreated speech and language delay are likely to exhibit diminished reading skills in grade school, poor verbal and spelling skills, behaviour problems and impaired psychosocial adjustment. Consequently, these problems may lead to overall academic underachievement, a lower intelligent quotient (IQ) that may persist into young adulthood (Nelson et al., 2006; USPSTF, 2006). Fifty percent of the subjects performed poorly academically in school (Table 3). Early assessment and intervention to correct their speech and language problems was not done. The involvement of speech-language therapists in Ghana's early school programmes to undertake such assignments is very necessary and must be considered.

The subjects appeared to have no obvious organic problem but Bernthal and Bankson (1981) stated that "An articulation disorder of unknown etiology, however, may be caused by one or more subtle organic, learning, or environmental factors". A carefully conducted oral peripheral examination identified some of the children's different tongue characteristics (Table 5), and in Ghana, the assumption that an infant or child with ankyloglossia should have his/her frenum clipped to allow greater freedom of tongue movement and

Table 3: Class performance of subjects

\begin{tabular}{lcccc}
\hline Class & Above Average & Average & Below Average & Total \\
\hline KG & - & 4 & 6 & 10 \\
LG & - & 8 & 5 & 13 \\
UG & - & 1 & 1 & 2 \\
JHS & - & 1 & 3 & 4 \\
SHS & 1 & - & - & 1 \\
Total & $1(3.3 \%)$ & $14(46.7 \%)$ & $15(50 \%)$ & $30(100 \%)$ \\
\hline
\end{tabular}

Table 4: Early language developmental status of subjects

\begin{tabular}{llll}
\hline Age & $\begin{array}{c}\text { Normal language } \\
\text { development }\end{array}$ & $\begin{array}{c}\text { Delayed language } \\
\text { development }\end{array}$ & Total \\
\hline $7-8$ & $8(26.7 \%)$ & $4(13.3 \%)$ & $12(40 \%)$ \\
$9-11$ & $4(13.3 \%)$ & $5(16.7 \%)$ & $9(30 \%)$ \\
$12-14$ & $3(10 \%)$ & $2(6.7 \%)$ & $5(16.7 \%)$ \\
$15-17$ & $4(13.3 \%)$ & - & $4(13.3 \%)$ \\
Total & $19(63.3 \%)$ & $11(36.7 \%)$ & $30(100 \%)$ \\
\hline
\end{tabular}

22 Journal of Science and Technology, Vol. 28, No. 2, August, 2008 
better articulation is very high among parents and carers (Osei-Bagyina, 2000b) but it is seldom a significant factor (Weiss et al., 1980). Researchers are warned that many of the concepts about oral-pharygeal structures and function, acceptable in the past are now totally unacceptable. There is, therefore, the need for more reliable decision about the adequacy of the speech mechanism, and the need for more adequate training (Pannbacker, 1985). Besides that, Dworkin and Culatta (1985) in a study of structural and/or neuromuscular aberrations in the speech mechanisms of children who were previously diagnosed as having "functional" articulation disorders and a group of normal articulating children saw no significant differences in the two groups in any of the measures.

As regards intervention, there is some evidence to support the effectiveness of speech and language therapy for children with phonological disorders or expressive difficulties (Law and
Garrett, 2004). As a SLT, the researcher knew from experience with individual children that different manifestations of phonological disorders respond best to different forms of therapy (Hesketh et al., 2000). He was also aware that interventions lasting more than 8 weeks seemed to be most effective (Law and Garrett, 2004). The consonants were of more concern to the speech therapist because more children have difficulty with consonants than with vowels (Weiss et al., 1980). Practice tasks, generally, worked through the target sounds in isolation, syllables, words and sentences. In the end, $73.3 \%$ of the subjects reached $90-100 \%$ degree of mastery; $20 \%$ reached $70-80 \%$ and $6.7 \%$ reached $50-60 \%$ degree of mastery in the correct use of the target sounds (Table 8) and thus improved their baseline intelligibility rate (Table 7).

There were spectacular improvements in the speech of most subjects. For example, TM, a 16year old JHS Form Two boy used some stereo-

Table 5: Tongue characteristics of subjects

\begin{tabular}{llcccc}
\hline Age & $\begin{array}{l}\text { Normal } \\
\text { tongue }\end{array}$ & Ankyloglossia & Macroglossia & $\begin{array}{l}\text { Limited tongue } \\
\text { movement }\end{array}$ & Total \\
\hline $7-8$ & 8 & 1 & - & 3 & 12 \\
$9-11$ & 3 & 2 & - & 4 & 9 \\
$12-14$ & 2 & 1 & - & 2 & 5 \\
$15-17$ & 2 & 1 & 1 & - & 4 \\
Total & $15(50 \%)$ & $5(16.7 \%)$ & $1(3.3 \%)$ & $9(30 \%)$ & $30(100 \%)$ \\
\hline
\end{tabular}

Table 6: Voice resonance characteristics of subjects

\begin{tabular}{lcccc}
\hline \multicolumn{1}{c}{ Age } & Normal voice & Hypernasal & Hyponasal & Total \\
\hline $7-8$ & 11 & 1 & - & 12 \\
$9-11$ & 6 & 3 & - & 9 \\
$12-14$ & 4 & 1 & - & 5 \\
$15-17$ & 3 & 1 & - & 4 \\
Total & $24(80 \%)$ & $6(20 \%)$ & 0 & $30(100 \%)$ \\
\hline
\end{tabular}


Table 7: Speech intelligibility rate of subjects

\begin{tabular}{llcll}
\hline \multicolumn{1}{c}{ Age } & Moderate & Moderate-severe & Severe & Total \\
\hline $7-8$ & 5 & 4 & 3 & 12 \\
$9-11$ & 2 & 3 & 4 & 9 \\
$12-14$ & 2 & 0 & 3 & 5 \\
$15-19$ & 0 & 2 & 2 & 4 \\
Total & $9(30 \%)$ & $9(30 \%)$ & $12(40 \%)$ & $30(100 \%)$ \\
\hline
\end{tabular}

Table 8: Speech therapy gains; subjects' degree of mastery

\begin{tabular}{cllccc}
\hline Age & $\mathbf{9 0 - 1 0 0 \%}$ & $\mathbf{7 0 - 8 0 \%}$ & $\mathbf{5 0 - 6 0 \%}$ & $\mathbf{5 0 \%} \&$ Below & Total \\
\hline $7-8$ & 9 & 2 & 1 & - & 12 \\
$9-11$ & 6 & 2 & 1 & - & 9 \\
$12-14$ & 4 & 1 & - & - & 5 \\
$15-17$ & 3 & 1 & - & - & 4 \\
Total & $22(73.3 \%)$ & $6(20 \%)$ & $2(6.7 \%)$ & 0 & $30(100 \%)$ \\
\hline
\end{tabular}

typed nasal substitution for almost all the consonants, no matter how different their resemblance. He was among the $20 \%$ hypernasal subjects treated (Table 6). He used gestures because he could not be understood. He failed and was repeating his class so he was not happy in the school. At the end of the therapy, he attained $100 \%$ degree of mastery in the production of all sounds and talked normally. It was a big surprise to his family. He soon took up leadership position in a youth movement in his church and attended meetings on the movement's behalf.

Like TM, every subject progressed to a point. Among the best predictors for therapy gains were the presence of treatment target in the subject's phonetic repertoire and good cognitive ability. Finally, identification and intervention of the children's articulation and phonological disorders improved their skills for effective communication, learning, emotional and behavioural adjustment, and a fully active social life.

\section{CONCLUSION}

In this study of articulation and phonological disordered children, males, as usual, outnumbered females. Over $90 \%$ of the children trailed behind their age mates at school while $50 \%$ performed below average academically. Also 36.7\% had untreated language delay which contributed to their poor academic performance. The different tongue characteristics did not pose any danger to therapy and nasality among some of the children was treated by improved articulation.

Baseline intelligibility rates were moderate- $30 \%$, moderate-severe $30 \%$ and severe- $40 \%$. The treatment gain gave the children improved skills for better communication and active social life.

\section{REFERENCES}

Amedofu, G. K., Opoku Buabeng, J., OseiBagyina, A. and Antwi, B. (2003). Hearing loss among school children in Ghana. Ghana Medical Journal. 37: 148-152.

Bernthal, J. E. and Bankson, N. W. (1981). Articulation Disorders. Prentice Hall, Inc. Englewood Cliff, pp. 2 -3.

Blelle, K. (2002). Evaluating articulation and phonological disorders when the clock is running. American Journal of SpeechLanguage Pathology. II: 243-49. 
Boon, D. R. and Plante, E. (1993). Human Communication and its Disorder. Prentice-Hall, New Jersey, pp. 256-58.

Bruce, B. and Sahlen, B. (1996). Identifying severe language disorders before age 3 years 6 months. Logopedics Phoniatrics Vocology. 21(1):37-42.

Dworkin, J. W. and Culatta, R. A. (1985). Oral structures and neuromuscular characteristics in children with normal and disordered articulation. Journal of Speech and Hearing Disorders. 50:150-156.

Emerick, L. L. and Hatten, J. T. (1979). Diagnosis and Evaluation in Speech Pathology $\left(2^{\text {nd }}\right.$ Ed). Prentice Hall, Inc. Englewood Cliff, p.157.

Hesketh, A., Adams, C., Nightingate, C. and Hall, R. (2000). Phonological awareness therapy and articulatory training approaches for children with phonological disorders: a comparative outcome study. Int. J. Lang. Comm. Disord. 35:337- 354.

Law, J. and Garrett, Z. (2004). The efficacy of treatment for children with developmental speech and language delay/disorder. Journal of Speech-Language, and Hearing Research. 47:924-943.

Nelson, H. D., Nygren, P., Walker, M. and Panoscha, R. (2006). Screen for Speech and Language Delay in Preschool Children. Rockville, MD: Agency for Health care Research and Quality. Available at: www.ahrq.gov/clinic/uspstfix.htm
NIH (1994). Articulation disorders of unknown children NIH Guide, 23 (7) February 18.

Osei-Bagyina, A. (2000a). Incidence of oral communication problems in patients at KATH, Ghana. Journal of Science and Technology, 20:125-131.

Osei-Bagyina, A. (2000b). Causes of child language disorders in patients at $\mathrm{KATH}, \mathrm{Ku}-$ masi, Ghana. Journal of Science and Technology, 20:132-138.

Oye, H. J., Hall, B. J. and Hass, W. H. (1994). Speech, Language and Hearing Disorders. Allyn and Bacon, Bosten, p.10.

Pannbacker, M. (1985). Common misconceptions about oral pharyngeal structure and function. Language, Speech and Hearing Services in Schools. 16:29-33.

US Preventive Services Task Force. (2006). Screening for speech and language delay in children: recommendation statement. Pediatrics 117: 497-501.

Weiss, C. E., Lillywhite, H. S. and Gorden, M. E. (1980). Clinical Management of Articulation Disorders. The C. V. Mosby Company, St Louis, pp 3,71, $73-74,80$.

Wikipedia (2007). Speech-Language Pathology in School Settings. http://en.wikipedia.org/wiki/ speech-language pathology in school settings 